\title{
Overweight and Obesity among Female Students in Sohag University and Factors Associated with their Occurrence
}

\author{
${ }^{1}$ Farida S. Abdou, ${ }^{2}$ Ahmed F. Hamed, ${ }^{2}$ Eman Roshdy And ${ }^{2}$ Nesreen A. Mohammed \\ ${ }^{1}$ Department of Family Medicine, Faculty of Medicine, ${ }^{2}$ Department of Public Health and \\ Community Medicine, Sohag University \\ Received: September, 2018 Accepted: November, 2018
}

\begin{abstract}
Background: Obesity is a medical disorder in which extra body fat is stored to the degree which may have a harmful effect on the health. People are generally measured obese when their body mass index (BMI) is $\geq 30 \mathrm{~kg} / \mathrm{m}^{2}$, with the range from $25-29.9 \mathrm{~kg} / \mathrm{m}^{2}$ is considered as overweight. However, some countries, especially in the East Asian area may use lower values to define both overweight and obesity. Objective: This study aimed at determining the proportion suffering from overweight and obesity among a sample of female students in Sohag university, and identifying factors associated with their occurrence. Method: A cross sectional study was carried out in faculties of medicine, nursing and education in Sohag university and included a sample of 600 female students aged 17-25 years in the selected faculties. The data was collected through personal interviews with the participating students using a questionnaire containing questions about sociodemographic variables, dietary habits, physical activity, perceptions of body weight and beliefs of obesity and the record of self-reported and actual anthropometric body measurements. Results: More than one third of participants (37.3\%) were overweight and $1.2 \%$ were obese. Lack of physical activity, consumption of soft drinks and marital status were significantly related to obesity. The participants preferred dairy products and fatty foods over vegetables and fruits. In addition, "lack of time" was the most frequently mentioned barrier to eating a healthy diet and being engaged in regular exercise. Conclusion: Overweight and obesity were detected in $38.5 \%$ of the participants. Life style modification is important to improve healthy habits earlier in life.
\end{abstract}

Key Words: Obesity, Female Students, Sohag University.

Corresponding Author: Farida S. Abdou Email: Abdelwahabfarida@Yahoo.Com

\section{Introduction}

Obesity is a medical disorder in which extra body fat is stored to the extent that it may have a harmful effect on the health. Generally, an individual is considered obese when his/her body mass index (BMI) is equal or higher than $30 \mathrm{~kg} / \mathrm{m}^{2}$, with the range from 25 to less than $30 \mathrm{~kg} / \mathrm{m}^{2}$ is defined as "overweight". BMI is obtained by dividing the person's weight (measured by kilograms) by the square of the person's height (measured by meters). Some East-Asian countries use values below 30 for the definition of obese and below 25 to define overweight. ${ }^{1,2}$
Generally talking, obesity is mostly caused by a combination of excess food intake, physical inactivity in genetically predisposed person or population. A little proportion is caused primarily by genes, endocrine diseases, medication, or mental illness. Suggestion to support the view that obese people eat minute yet gain weight due to a slow metabolism is not generally maintained. On usual, obese people have better energy expenditure compared to thin comparer due to the excess energy required to maintain the increased body mass. Obesity increases the 
probability of many diseases, notably heart diseases, type 2 diabetes mellitus, obstructive sleep apnea syndrome, osteoarthritis and even some types of cancers. ${ }^{3}$

The percentage of obese or overweight adolescents is rapidly increasing globally. Adolescence is a susceptible period for the development of obesity and also appears to be a serious period for creating risk factors for some chronic diseases in adulthood. Existing statistics indicate that an alarming percentage of people in most Arab countries were suffered from obesity. Studies have exposed that the incidence of overweight and obesity among adolescents in arab countries ranges from $18 \%$ to $44 \% .^{4}$

Overall, overweight has been found to be more predominant than obesity in both sexes. In countries such as Egypt, Bahrain, Kuwait, Qatar and Tunisia, the incidence of overweight is higher among females. In other countries such as Lebanon and the United Arab Emirates (UAE), the incidence of overweight and obesity is higher in males. ${ }^{4}$

This study aimed at determining the proportion suffered from overweight and obesity among a sample of female students in Sohag university, and identifying factors associated with their occurrence.

\section{Methods}

Design: a cross sectional study. Site: this study was done in three faculties (faculty of medicine, faculty of nursing and faculty of education) in sohag university. Sample size: The calculated sample size was 498 based on the following assumption: the prevalence $25 \%$ as demonstrated in the study done by fouad et al. $2016^{(5)}$, power as $80 \%$, and the confidence level as $99 \%$. However, by considering the response rate of $80 \%$, the sample size was increased to 600 students.
Sampling technique: Students were selected using the multistage stratified random sampling technique as follow: faculties in the university were divided into medical and non-medical faculties. Therefore, faculties were chosen randomly from each stratum; faculty of medicine and faculty of nursing were chosen from the medical faculties and faculty of education was chosen from the non-medical faculties.

The number of the students chosen from each faculty was determined proportionally to the total number of the students in each faculty.

Stratification of the educational grades in each faculty was done and from each grade, students were selected by clustered random sampling technique based on the proportion of the students in this grade to the total number of students in the faculty.

Data collection: Data was collected, using a validated questionnaire used in the study done by Ilesanmi-Oyelere B1 ${ }^{6}$ and inquiring data about sociodemographic variables, dietary habits, physical activity, perceptions of body weight and beliefs of obesity and the record of self-reported and actual anthropometric body measurements, through personal interviews with the female students from the predetermined places after explaining the nature and the aim of the study.

Weight and standing height were measured by trained personnel with the students barefooted. Measurements were approximated to the nearest $0.5 \mathrm{~kg}$ for weight and the nearest $1 \mathrm{~cm}$ for height, and then bmi was calculated to determine overweight and obesity using who international standards.

Statistical analysis:

Computer data entry and data cleaning done along the period spent on data collection. Data subjected to statistical analysis and tabulation using SPSS program version 22, quantitative data 
were expressed as means \pm standard deviation. The data were tested for normality using Shapiro-Wilk test which showed that the data was normally distributed, and such indicating the use of parametric tests. Data was analyzed by using independent samples t-test. Chisquare $(\chi 2)$ test was used for comparison regarding qualitative variables, univariate and multiple logistic regression tests were used to determine factors associated with obesity among studied population. A 5\% level was chosen as a level of significance in all statistical tests used in the study.

\section{Ethical consideration:}

The ethical committee of Sohag faculty of medicine approved the research proposal. A written informed consent was signed by the participants after explaining the objectives and the steps of the study to them. Ethical consideration was observed in each step of the study including written consent of the participants. The questionnaire used in data collection was anonymous and confidentiality was assured.

\section{Results}

The total number of participants in this study was 600 females, included 369 (61.5\%) participants with normal BMI $(18.5$ - 24.9), while $224 \quad(37.3 \%)$ participants were overweight (BMI 25 29.9), and $7(1.2 \%)$ students were obese $(\mathrm{BMI} \geq 30)$ as shown in figure 1 . Weight, height, waist circumference and BMI of the participants were summarized in table 1 . The mean value of weight was $56.6 \mathrm{~kg}$ in the normal group while the mean value of weight was $70.9 \mathrm{~kg}$ in the overweight and obese group. In addition, the mean value of height was about 159 $\mathrm{cm}$ in both groups. The average waist circumference was 72.3 in the normal group while it was 80.9 in the other group. The mean value of BMI was 22.5 in the normal group and 27.9 in the overweight and obese group. All these

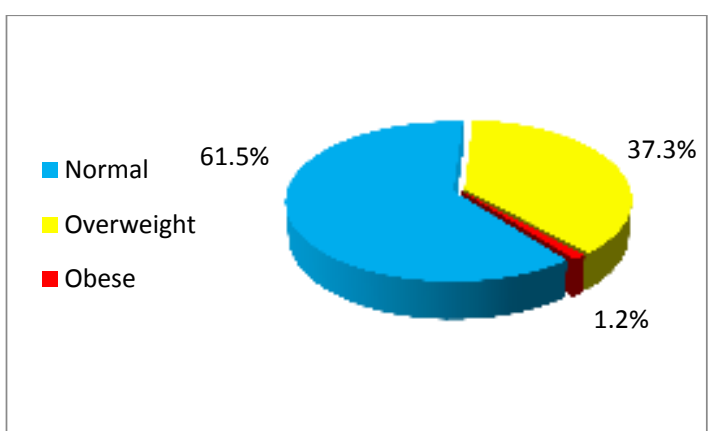

Figure (1). BMI Distribution in Female Students in Sohag University

differences were highly significant $(\mathrm{p}<0.001)$, except for the height as it was non-significant.

Dietary behaviors and food consumption patterns of our participants and their relations with BMI are summarized in table 2. The findings showed a significant relationship between BMI status and breakfast intake $(\mathrm{p}=0.008)$.

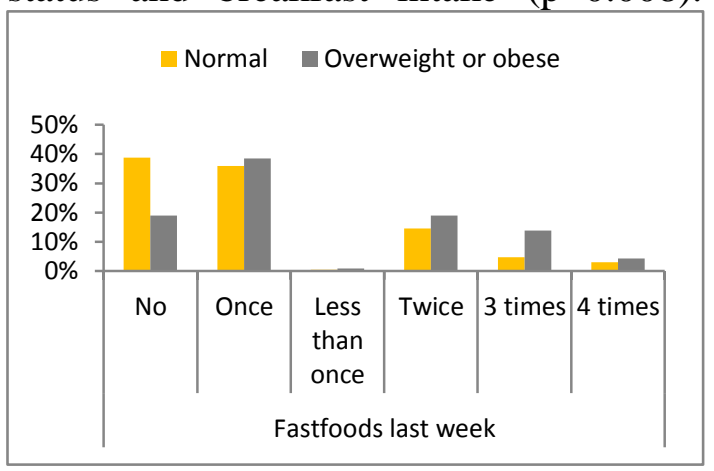

Figure (2): Fast Foods Consumption by Study Participants per Week

More than one fifth (20.9\%) of the participants in the normal group reported that they always ate breakfast compared to $16.9 \%$ of the overweight or obese students. Over thirty-five percent $(35.9 \%)$ of overweight or obese participants had breakfast intake for 1019 times per month compared to $37.4 \%$ of the normal group.

The main reason for skipping breakfast among overweight or obese participants was lack of time $(29.4 \%)$, also it was the main cause among the normal participants $(33.5 \%)$. Fruits seem to be consumed at least once per day by most participants in both groups. There was no association between the BMI status of participants and fruits consumption. 


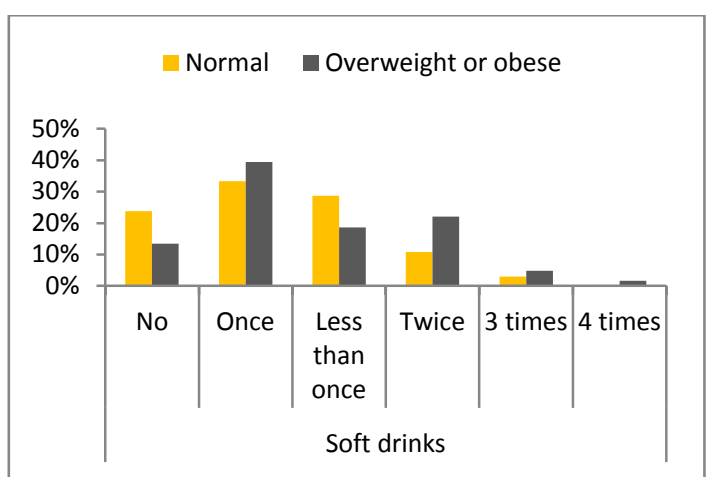

Figure (3): Soft Drinks Consumption per Day

Figures 2 showed a highly significant association $(\mathrm{p}<0.001)$ between fast foods consumption and respondents' BMI, on which we found that $(38.8 \%)$ of normal participants didn't take fast foods during the last week, while $(38.5 \%)$ of overweight or obese participants had taken fast foods once a week.

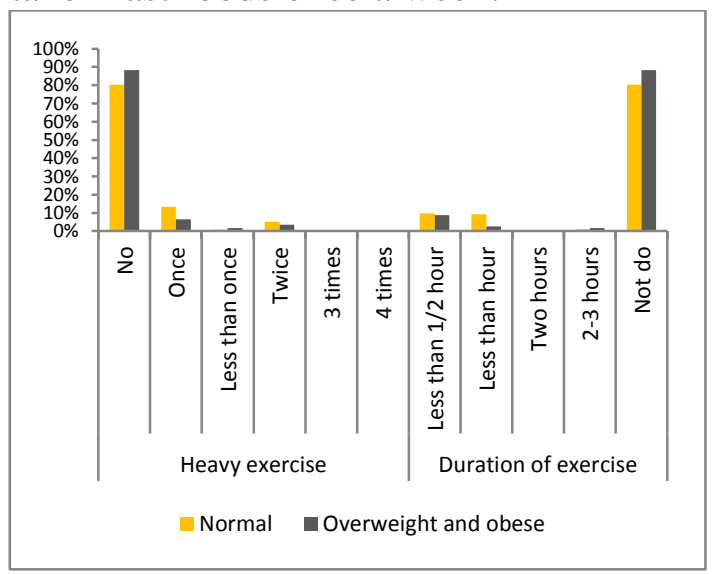

Figure (4): Details Of Participants' Heavy Exercise Per Week

Additionally figure 3 showed a highly significant association between BMI status and soft drinks consumption $(p<0.001)$. About $(39.4 \%)$ of overweight or obese participants consumed soft drink once daily while. However, 33.3\% of normal participants consumed soft drinks once daily. (23.8\%) of normal participants not drinks any soft drinks while only $13.4 \%$ of overweight or obese participants not drink any soft drinks.

Dairy products and consumption of fatty food is summarized in table 3. Dairy products and fatty food ingesting was significantly related to the BMI status $(\mathrm{p}=0.01,0.002$ respectively). More than $12 \%$ of the normal participants had no dairy products, $48.8 \%$ consumed dairy products once daily, $18.7 \%$ had dairy products twice daily while $3.8 \%$ had dairy products three times daily, on the other hand, $8.2 \%$ of overweight or obese participants had no dairy products, $47.6 \%$ consumed dairy products once daily, $27.3 \%$ had dairy products twice daily while $6.5 \%$ had dairy products three times daily. Regarding fatty foods, we found that about (38\%) of the participants in overweight or obese group consumed fatty food twice and $(38 \%)$ of participants in normal group consumed fatty food once during the last month Figure (4) showed the details of the participants' heavy exercise. The relation between BMI status and heavy exercise was significant (p-value $=0.04$ ) and similarly, the relation between BMI status and the duration of exercise $(\mathrm{p}=0.01)$.

Regression analysis was used to detect predictor variables of overweight and obesity among the participants and these variables were summarized in tables 4,5 , 6. All possible variables were introduced into a univariate binary logistic regression analysis. The factors which showed non-significant effect were excluded from the subsequent analysis.

Univariate analysis showed marital status (p-value <0.001), exercise (p-value $=0.01)$ soft drinks (p-value $=0.05)$, watching TV (p-value=0.05) were significantly associated with obesity, while age, breakfast, eating fruits and vegetables, and walking 10 minutes were not. Factors which showed a significant effect by univariate regression were evaluated for possible association and interaction, by multivariate regression analysis (table 6) showed that marital state ( $\mathrm{p}$-value $<0.001$, or $=3.38$ ), exercise ( $\mathrm{p}$-value $=0.017$, or $=1.17)$, and watching TV $(\mathrm{p}=0.031, \mathrm{OR}=0.5)$ were independent factors that predict the overweight or obese participants from the normal BMI participants. 
Table 1. Weight, Height, Waist Circumference And BMI Of Participants

\begin{tabular}{|l|c|c|c|}
\hline Variable & $\begin{array}{c}\text { Normal Group } \\
\text { (BMI= (18.9-24.9) } \\
\text { (Mean } \pm \text { SD) } \\
\mathbf{N}(\mathbf{3 6 9})\end{array}$ & $\begin{array}{c}\text { Overweight And Obese } \\
\text { Group (BMI } \geq \mathbf{2 5}) \\
(\text { Mean } \pm \text { SD) } \\
\mathbf{N}(\mathbf{2 3 1})\end{array}$ & P Value \\
\hline Weight & $56.67 \pm 5.46$ & $70.90 \pm 6.65$ & $<\mathbf{0 . 0 0 1 *}$ \\
\hline Height & $158.63 \pm 3.88$ & $159.16 \pm 3.19$ & 0.08 \\
\hline Waist Circumference & $72.39 \pm 5.22$ & $80.96 \pm 5.56$ & $<\mathbf{0 . 0 0 1 *}$ \\
\hline BMI & $22.51 \pm 1.83$ & $27.94 \pm 2.18$ & $<\mathbf{0 . 0 0 1}^{*}$ \\
\hline
\end{tabular}

P- Value Was Calculated By Student-T Test *Statistically Significant

Table 2. Dietary Behaviors and Food Consumption Patterns

\begin{tabular}{|c|c|c|c|c|}
\hline & Variable & $\begin{array}{c}\text { Normal Group } \\
\text { (BMI= }(18.9-24.9) \\
\text { No }(\%) \\
\text { 369 }(100 \%)\end{array}$ & $\begin{array}{l}\text { Overweight and } \\
\text { Obese Group } \\
\text { (BMI } \geq 25) \\
\text { No }(\%) \\
231(100 \%) \\
\end{array}$ & $\begin{array}{l}P \\
\text { Value }\end{array}$ \\
\hline \multirow{5}{*}{ 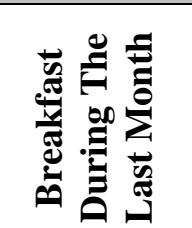 } & No & $17(4.6 \%)$ & $12(5.2 \%)$ & \multirow{5}{*}{ 0.008* } \\
\hline & 1_9/Month & $94(25.5 \%)$ & $85(36.8 \%)$ & \\
\hline & 10_19/Month & $138(37.4 \%)$ & $83(35.9 \%)$ & \\
\hline & 20_29/Month & $43(11.7 \%)$ & $12(5.2 \%)$ & \\
\hline & Always & $77(20.9 \%)$ & $39(16.9 \%)$ & \\
\hline \multirow{6}{*}{ 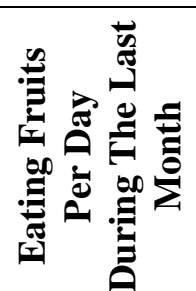 } & No & $15(4.1 \%)$ & $15(6.5 \%)$ & \multirow{6}{*}{0.119} \\
\hline & Once Daily & $160(43.4 \%)$ & $90(38.9 \%)$ & \\
\hline & Less Than Once Daily & $49(13.3 \%)$ & $31(13.4 \%)$ & \\
\hline & Twice Daily & $113(30.6 \%)$ & $75(32.5 \%)$ & \\
\hline & 3 Times Daily & $26(7 \%)$ & $20(8.7 \%)$ & \\
\hline & 4 Times Daily & $6(1.6 \%)$ & $0(0 \%)$ & \\
\hline
\end{tabular}

\section{Discussion}

The total number of the participants in this study was 600 females, included 369 (61.5\%) participants with normal BMI (18.5 - 24.9), while $224(37.3 \%)$ participants were overweight (BMI 25 29.9), and $7(1.2 \%)$ students were obese $(\mathrm{BMI} \geq 30)$. These findings were similar to the results of Lowry et al. ${ }^{7}$ who reported that $35 \%$ of college students were overweight or obese, and Silliman et al. ${ }^{8}$ who reported that $31 \%$ of female population had a BMI greater than 25 . Our results were higher than the results of Sengupta et al. ${ }^{9}$ in India where the prevalence of overweight was $11.3 \%$ and that of obesity was $8.1 \%$.
The prevalence of obesity in the united states is considered high, in fact exceeding $30 \%$ in most of the sex and age groups. ${ }^{10}$ A review of prevalence in European countries reported that the prevalence of obesity varies widely from country to country, with higher prevalence in eastern, central and southern countries. ${ }^{11}$ Generally, the prevalence of obesity is lower in European countries compared the united states in most of studies. However, estimates from countries other than European ones are not exactly comparable with us studies due to different methodologies, duration of studies and the age ranges of the 
Table 3. Dairy Products And Fatty Food

\begin{tabular}{|c|c|c|c|c|}
\hline \multicolumn{2}{|l|}{ Variable } & $\begin{array}{l}\text { Normal Group } \\
\begin{array}{c}\text { (BMI }=(18.9- \\
24.9) \\
\text { No }(\%) \\
369(100 \%)\end{array}\end{array}$ & $\begin{array}{l}\text { Overweight And } \\
\text { Obese Group } \\
\text { (BMI } \geq 25) \\
\text { No }(\%) \\
231(100 \%)\end{array}$ & $\begin{array}{l}\text { P- } \\
\text { Value }\end{array}$ \\
\hline \multirow{6}{*}{ 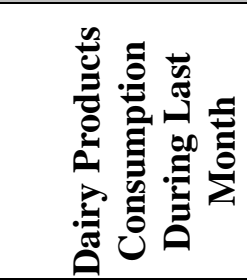 } & No & $47(12.7 \%)$ & $19(8.2 \%)$ & \multirow{6}{*}{$0.01 *$} \\
\hline & Once Daily & $180(48.8 \%)$ & $110(47.6 \%)$ & \\
\hline & Less Than Once Daily & $56(15.2 \%)$ & $21(9.1 \%)$ & \\
\hline & Twice Daily & $69(18.7 \%)$ & $63(27.3 \%)$ & \\
\hline & 3 Times Daily & $14(3.8 \%)$ & $15(6.5 \%)$ & \\
\hline & 4 Times Daily & $3(0.8 \%)$ & $3(1.3 \%)$ & \\
\hline \multirow{8}{*}{ 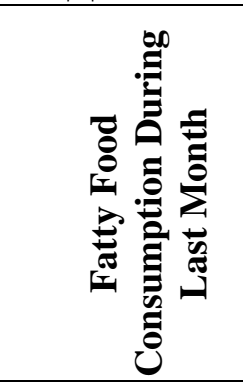 } & No & $3(0.8 \%)$ & $2(0.9 \%)$ & \multirow{8}{*}{$0.002 *$} \\
\hline & Once Daily & $140(37.9 \%)$ & $72(31.1 \%)$ & \\
\hline & Less Than Once Daily & $45(12.2 \%)$ & $10(4.3 \%)$ & \\
\hline & Twice Daily & $124(33.6 \%)$ & $88(38.1 \%)$ & \\
\hline & 3 Times Daily & $35(9.5 \%)$ & $39(16.9 \%)$ & \\
\hline & 4 Times Daily & $19(5.1 \%)$ & $17(7.4 \%)$ & \\
\hline & 5 Times Daily & $1(0.4 \%)$ & $0(0 \%)$ & \\
\hline & More Than 5 Daily & $2(0.5 \%)$ & $3(1.3 \%)$ & \\
\hline
\end{tabular}

Table 4. Univariate Binary Regression Analysis Between Normal Participants And Overweight Or Obese Participants

\begin{tabular}{|l|c|c|c|c|}
\hline \multirow{2}{*}{} & \multirow{2}{*}{ Odd's Ratio } & \multicolumn{2}{|c|}{$\begin{array}{c}\text { CI For Odd's } \\
\text { Ratio }\end{array}$} & \multirow{2}{*}{ P-Value } \\
\cline { 3 - 4 } & & Lower & Upper & \\
\hline Age & 1.000 & 0.895 & 1.119 & 0.994 \\
\hline Marital Status & 3.515 & 1.809 & 6.830 & $<\mathbf{0 . 0 0 1}$ \\
\hline Breakfast & 1.607 & 0.100 & 25.818 & 0.738 \\
\hline Eating Fruits & 1.644 & 0.769 & 3.514 & 0.200 \\
\hline Eating Vegetables & 0.000 & 0.000 &. & 1.000 \\
\hline Soft Drinks & 0.524 & 0.273 & 1.007 & $\mathbf{0 . 0 5}$ \\
\hline Exercise & 1.789 & 1.125 & 2.845 & $\mathbf{0 . 0 1 4}$ \\
\hline Watching TV & 0.543 & 0.294 & 1.004 & $\mathbf{0 . 0 5}$ \\
\hline Walking 10 Minutes & 0.000 & 0.000 &. & 0.999 \\
\hline
\end{tabular}

participants, and methods of age adjustment or categorization into age groups. $^{11}$

Breakfast is a very important meal of the day since it gives the energy needed for going about the day's activities. The findings showed a significant relationship. Between BMI status and breakfast intake $(\mathrm{p}=0.008)$ and the reason for no breakfast intake ( $\mathrm{p}<0.001$ ). More than four percent $(4.6 \%)$ of the participants in the normal group never had breakfast and $5.2 \%$ of the other study group never had breakfast. More than one fifth $(20.9 \%)$ of the participants in the normal group reported that they always ate breakfast during the last month compared to $16.9 \%$ of the overweight or obese students. Over thirty-five percent $(35.9 \%)$ of overweight or obese participants had breakfast intake for 10-19 times per month compared to $37.4 \%$ of the normal group. The main reason for skipping breakfast among the overweight or obese participants and even among normal weight persons was lack of time. However, another research done in Lebanon stated that over $60 \%$ of university students had regular meals daily. ${ }^{12}$ As reported by many studies, skipping breakfast is a proven factor to induce obesity, because it results in lack 
Table 5. Multivariable Binary Regression Analysis between Normal Participants and Overweight or Obese Participants.

\begin{tabular}{|l|l|l|l|c|}
\hline \multirow{2}{*}{} & \multirow{2}{*}{ Odd's Ratio } & \multicolumn{2}{|c|}{$\begin{array}{l}\text { CI For Odd's } \\
\text { Ratio }\end{array}$} & \multirow{2}{*}{ P-Value } \\
\cline { 3 - 4 } & & Lower & Upper & \\
\hline Marital Status & 4.295 & 0.150 & 0.578 & $<\mathbf{0 . 0 0 1}$ \\
\hline Soft Drinks & 0.540 & 0.278 & 1.050 & 0.079 \\
\hline Exercise & 1.772 & 1.106 & 2.840 & $\mathbf{0 . 0 1 7}$ \\
\hline Watching TV & 0.52 & 0.279 & 0.980 & $\mathbf{0 . 0 4 3}$ \\
\hline
\end{tabular}

Table 6. Final Model Of Multivariable Logistic Regression.

\begin{tabular}{|l|l|l|l|c|}
\hline & \multirow{2}{*}{ Odd's Ratio } & \multicolumn{2}{l|}{$\begin{array}{l}\text { CI For Odd's } \\
\text { Ratio }\end{array}$} & P-Value \\
\cline { 3 - 4 } & & Lower & Upper & \\
\hline Marital Status & 3.383 & 1.730 & 6.614 & $<\mathbf{0 . 0 0 1}$ \\
\hline Exercise & 1.771 & 1.106 & 2.834 & $\mathbf{0 . 0 1 7}$ \\
\hline Watching TV & 0.50 & 0.269 & 0.941 & $\mathbf{0 . 0 3 1}$ \\
\hline
\end{tabular}

of satiety feeling thus leading to increased energy intake. ${ }^{13}$

We demonstrated that the relation between fast foods consumption and respondents' BMI status, more than one third of the normal participants $(38.8 \%)$ didn't take fast foods in the last week while more than one third of the overweight or obese participants (38.5\%) had taken fast foods once last week. Comparable results were found in a Malaysian study in which $21.2 \%$ of the respondents consumed fast-food. ${ }^{14}$ In contrast, Moy et al. ${ }^{15}$ reported that $60-70 \%$ of the students were habitually consuming fast food.

Furthermore, the current study reported a highly significant association between BMI status and soft drinks $(\mathrm{p}<0.001)$. More than one third (39.4\%) of the overweight or obese participants consumed soft drink once daily and $1.7 \%$ reported 4 times consumption. However, $33.3 \%$ the participants with normal weight consumed soft drinks once daily. More than one fifth $(23.8 \%)$ of the students in the normal group didn't drink any soft drinks compared to $13.4 \%$ of the overweight or obese participants. Similarly, a study was conducted by Malik VS et al, showed that $11.7 \%$ of the students consumed soft drink at least three or four times per week. High intake of soft drink led to high risk of chronic disease such as diabetes mellitus and hypertension. Moreover, the prevalence of overweight and obesity was increasing due to high consumption of sugar-sweetened beverages. ${ }^{16}$

In our study, the dairy products and fatty food consumption was significantly associated with the BMI status ( $\mathrm{p}=0.01$, 0.002 respectively). $12.7 \%$ of the normal participants didn't consume dairy products, $48.8 \%$ consumed dairy products once daily, $18.7 \%$ consumed dairy products twice daily while $3.8 \%$ consumed dairy products three times daily, on the other hand, $8.2 \%$ of overweight or obese participants reported no dairy products consumption, $47.6 \%$ consumed dairy products once daily, 27.3\% consumed dairy products twice daily while $6.5 \%$ consumed dairy products three times daily. In addition, regarding fatty food, we found that the participants in the overweight or obese group consumed fatty food twice 
daily but the participants in the normal group consumed fatty food once daily.

There was no association between the BMI status of participants and fruit consumption in the current study and similarly, in Canada, Janssen et al. ${ }^{17}$ have shown that no fruit consumption was associated with elevated BMI level among adolescents. A study done on adolescents in the USA by Neumaker-sztainer et $\mathrm{al}^{18}$ showed that overweight or obese participants or those who were not satisfied with their own body weight consumed significantly less fruits and greens than those with average weight. A study done on university students in Spain showed that there was significant low consumption of fruits and vegetables compared to the diet quality index among their participants. ${ }^{19}$

Regarding activity, we found that the relation between BMI status and heavy exercise $(p=0.04)$ and the duration of exercise $\quad(p=0.01) \quad$ were significant. However, BMI status was non-significantly associated with cause if no activity.

Regression analysis identified marital state, lack of physical activity, and watching TV are considered as independent factors that predict obesity. These findings were similar to what was reported by Menezes et al. ${ }^{20}$ as the results of their study showed that the time spent in watching TV, playing videogames and computers and physical inactivity significantly associated with weight in univariate analysis, while losing significance in the multivariate analysis. A study done in Spain on adolescents with or without weight gain showed that the level of physical activity among boys was significantly greater than females. ${ }^{21}$ Another case-control study carried out in Brazil by Monteiro et al. ${ }^{22}$ showed that there was no association between physical activity and overweight or obesity. Similar results were described in other case-control studies done by Neutzling et al. ${ }^{23}$ and Silveira et al. ${ }^{24}$
However, other studies found that college students, regardless of sex, have generally non healthy eating habits, which may be due to the limited time available for them to eat because of their study duties. ${ }^{25,26}$ Additional studies suggested that lack of interest or motivation; lack of energy; lack of knowledge; physical disability or injury and cost are the main barriers against physical activity. ${ }^{27}$

\section{Conclusion}

More than one third $(38.5 \%)$ of the participants, suffered from overweight or obesity. Lack of physical activity, consumption of soft drink and marital status were significantly associated with obesity. The participating students preferred dairy products and fatty foods over vegetables and fruits. In addition, their "lack of time" was the most frequently mentioned barrier to eating a healthy diet and engaging in regular exercise. Marital state, exercise, and watching TV were independent factors that predict overweight or obesity among the studied females. Life style modification is important to improve healthy habits earlier in life. Stress should be given to applying interventions aimed at limiting physical inactivity and encouraging healthy diets among students thus reducing future risk of chronic diseases caused by them.

\section{References}

1. Kanazawa M, Yoshiike N, Osaka T, Numba Y, Zimmet P, Inoue S. Criteria and Classification of Obesity in Japan and AsiaOceania. World Review Of Nutrition And Dietetics. 2005;94:1-12.

2. Wadden TA, Webb VL, Moran $\mathrm{CH}$, Bailer BA. Lifestyle Modification For Obesity: New Developments In Diet, Physical Activity, And Behavior Therapy. Circulation. 2012;125(9):1157-70. 
3. Haslam DW, James WP. Obesity. Lancet. 2005;366(9492):1197-209.

4. Musaiger AO, Hassan AS, Obeid O. The Paradox Of Nutrition-Related Diseases In The Arab Countries: The Need For Action. International Journal Of Environmental Research And Public Health. 2011;8(9):3637-71.

5. Fouad M, Ismail MI, Gaballah A, Reyad E, Et Al. Prevalence Of Obesity And Risk Of Chronic Kidney Disease Among Young Adults In Egypt. Indian Journal Of Nephrology. 2016;26(6):413-8.

6. Ilesanmi-Oyelere BL. Influence Of Lifestyle Choices And Risk Behaviours For Obesity Among Young Adult Women In The United Arab Emirates University: University Of Canterbury Te Whare Wananga $\mathrm{O}$ Waitaha Christchurch, New Zealand December, 2011

7. Lowry R, Galuska DA, Fulton JE, Weschler H, Kann L, Collins JL. Physical Activity, Food Choice, And Weight Management Goals And Practices Among US College Students. AJPM. 2000;18:1827.

8. Silliman K, Rodas-Fortier K, Neyman M. A Survey Of Dietary And Exercise Habits And Perceived Barriers To Following A Healthy Lifestyle In A College Population. Californian J Health Promot. 2004;2(2):109.

9. Sengupta A, Angeli F, Syamala TS, Dagnelie PC, Van Schayck CP. Overweight And Obesity Prevalence Among Indian Women By Place Of Residence And SocioEconomic Status: Contrasting Patterns From 'Underweight States' And 'Overweight States' Of India. Social Science \& Medicine. 2015;138:161-9.

10. Tjepkema M. Adult Obesity. Health Reports. 2006;17(3):9-25.

11. Berghofer A, Pischon T, Reinhold T, Apovian CM, Sharma AM, Willich SN. Obesity Prevalence From A European
Perspective: A Systematic Review. BMC Public Health. 2008;8:200.

12. Yahia N, Achkar A, Abdallah A, Rizk S. Eating Habits And Obesity Among Lebanese University Students. Nutrition Journal. 2008;7:32.

13. Horikawa C, Kodama S, Yachi Y, Heianza Y, Hirasawa R, Ibe Y, Et Al. Skipping Breakfast And Prevalence Of Overweight And Obesity In Asian And Pacific Regions: A Meta-Analysis. Preventive Medicine. 2011;53(4-5):260-7.

14. Ganasegeran K, Al-Dubai SA, Qureshi AM, Al-Abed AA, Am R, Aljunid SM. Social And Psychological Factors Affecting Eating Habits Among University Students In A Malaysian Medical School: A CrossSectional Study. Nutrition Journal. 2012;11:48.

15. Moy FM, Johari S, Ismail Y, Mahad R, Tie FH, Wan Ismail WA. Breakfast Skipping And Its Associated Factors Among Undergraduates In A Public University In Kuala Lumpur. Malaysian Journal Of Nutrition. 2009; 15 (2);74-165.

16. Malik VS, Schulze MB, Hu FB. Intake Of Sugar-Sweetened Beverages And Weight Gain: A Systematic Review. The American Journal Of Clinical Nutrition. 2006;84(2):274-88.

17. Janssen I, Katzmarzyk PT, Boyce WF, King MA, Pickett W. Overweight And Obesity In Canadian Adolescents And Their Associations With Dietary Habits And Physical Activity Patterns. The Journal Of Adolescent Health : Official Publication Of The Society For Adolescent Medicine. 2004;35(5):360-7.

18. Neumark-Sztainer D, Story M, Resnick MD, Blum RW. Correlates Of Inadequate Fruit And Vegetable Consumption Among Adolescents. Preventive Medicine. 1996;25(5):497-505.

19. Arroyo Izaga M, Rocandio Pablo AM, Ansotegui Alday L, Pascual Apalauza E, Salces Beti I, Rebato Ochoa E. [Diet 
Quality, Overweight And Obesity In University Students]. Nutricion Hospitalaria. 2006;21(6):673-9.

20. Neutzling MB, Hallal PR, Araujo CL, Horta BL, Vieira Mde F, Menezes AM, Et Al. Infant Feeding And Obesity At 11 Years: Prospective Birth Cohort Study. International Journal Of Pediatric Obesity : IJPO : An Official Journal Of The International Association For The Study Of Obesity. 2009;4(3):143-9.

21. Garaulet M, Martinez A, Victoria F, Perez-Llamas F, Ortega RM, Zamora S. Difference In Dietary Intake And Activity Level Between Normal-Weight And Overweight Or Obese Adolescents. Journal Of Pediatric Gastroenterology And Nutrition. 2000;30(3):253-8.

22. Monteiro P, Victora C, Barros F. [Social, Familial, And Behavioral Risk Factors For Obesity In Adolescents]. Revista Panamericana De Salud Publica = Pan American Journal Of Public Health. 2004;16(4):250-8.

23. Neutzling MB, Taddei JA, Gigante DP. Risk Factors Of Obesity Among Brazilian
Adolescents: A Case-Control Study. Public Health Nutrition. 2003;6(8):743-79

24. Silveira D, Taddei JA, Escrivao MA, Oliveira FL, Ancona-Lopez F. Risk Factors For Overweight Among Brazilian Adolescents Of Low-Income Families: A Case-Control Study. Public Health Nutrition. 2006;9(4):421-8.

25. Chen G, Liu C, Yao J, Jiang Q, Chen N, Huang H, Et Al. Overweight, Obesity, And Their Associations With Insulin Resistance And Beta-Cell Function Among Chinese: A Cross-Sectional Study In China. Metabolism: Clinical And Experimental. 2010;59(12):1823-32.

26. Al-Rethaiaa AS, Fahmy AE, AlShwaiyat NM. Obesity And Eating Habits Among College Students In Saudi Arabia: A Cross Sectional Study. Nutrition Journal. 2010;9:39.

27. Siddiqi Z, Tiro JA, Shuval K. Understanding Impediments And Enablers To Physical Activity Among African American Adults: A Systematic Review Of Qualitative Studies. Health Education Research.2011;26(6):1010-2. 